удК 65.007

К. А. Кешиков

Байкальский государственный университет, г. Иркутск, Российская Федерация

\title{
ПУТИ ВЛИЯНИЯ ИНФОРМАЦИОННО-КОММУНИКАЦИОННЫХ ТЕХНОЛОГИЙ НА СИСТЕМУ УПРАВЛЕНИЯ ПРОЦЕДУРОЙ ОЦЕНКИ ЗНАНИЙ И УЧЕТ ТЕКУЩЕЙ УСПЕВАЕМОСТИ В СОВРЕМЕННОМ ВУЗЕ
}

\begin{abstract}
АНнотАЦия. В статье поднимается проблема определяющего воздействия информационно-коммуникационных технологий на сферу образования на современном этапе развития государства, подчеркивается недостаточный уровень изученности направлений их влияния на систему управления процедурой оценки знаний и учетом текущей успеваемости обучаемых. Обозначены основные пути влияния, связанные со сменой стратегии управления системой оценивания знаний и учетом текущей успеваемости, повышением производительности труда, заменой способа функционирования процесса производства с преобразованием самих услуг по учету текущей успеваемости и процедур оценки знаний и форме информации о них. Выявлены специфика способов выполнения видов соответствующей деятельности и особенности природы связей между ними. По ходу исследования определены возможности информационно-коммуникационных технологий в направлении создания интеллектуальной поддержки за счет использования алгоритмических, математических и структурных методов принятия управленческих решений в исследуемой области. Сделаны выводы о месте информационно-коммуникационных технологий в качестве определяющего критерия степени успешности деятельности современного вуза; о роли информационной коммуникации как важной ценностной составляющей системы учета текущей успеваемости и процедур оценки знаний; о назначении информационно-коммуникационных технологий, трансформирующих сам способ бытия и качество жизнедеятельности участников информационной коммуникации в системе оценивания знания и учета текущей успеваемости.

КЛЮчЕВЫЕ СЛОВА. Пути; влияние; информационно-коммуникационные технологии; учет текущей успеваемости; процедуры оценки знаний.

ИНФОРМАЦИЯ О СТАТЬЕ. Дата поступления 12 марта 2016 г.; дата принятия к печати 25 мая 2016 г.; дата онлайн-размещения 29 июля 2016 г.
\end{abstract}

\author{
K. A. Keshikov \\ Baikal State University, \\ Irkutsk, Russian Federation
}

\section{WAYS OF INFLUENCE OF INFORMATION AND COMMUNICATION TECHNOLOGIES ON SYSTEM OF MANAGING THE PROCEDURE OF KNOWLEDGE EVALUATION AND RECORDING} OF CURRENT ACADEMIC PERFORMANCE IN PRESENT-DAY UNIVERSITIES

\begin{abstract}
The article brings up a concern of the determining impact of information and communication technologies on the educational sphere at the present stage of sate development, emphasizes the insufficient level of mastery of studies of the directions of their influence on the system of managing the procedure of knowledge evaluation and recording of students' current academic performance. It specifies the main ways of influence connected with change of strategy of managing the system of knowledge evaluation and recording of current academic performance, increasing labor productivity, replacement of ways of functioning the production process with transformation of services in recording of current academic performance and procedures of knowledge evaluation and the form of information about them. It identifies the specifics of ways for implementing certain types of related activities and the features of communication nature of between them. While investigating, it specifies the ICT possibilities in the
\end{abstract}

(C) К.А. Кешиков, 2016

\section{Baikal Research Journal}

электронный научный журнал Байкальского государственного университета 
direction of creating intellectual support due to using algorithmic, mathematical and structural methods of making administrative decisions in the area studied. Conclusions are made about the place of information and communication technologies as a determining criterion of the success degree for the present-day university; about the role of information communication as an important value-conscious constituent in the system of recording of current academic performance and procedure of knowledge evaluation; about the assignation of ITC technologies that transform the very way of being and living ability quality of the information communication participants in the system of knowledge evaluation and recording of current academic performance.

KEYWORDS. Ways; influence; information and communication technologies; recording of current academic performance; procedures of knowledge evaluation.

ARTICLE INFO. Received March 12, 2016; accepted May 25, 2016; available online July 29, 2016.

Информационная революция (как производная компьютеризации) резко расширяет интеллектуально-производственную мощь человека и делает возможным массовое производство когнитивной информации и систематизированного знания [1]. Благодаря чему информатизация напрямую и радикально влияет на сферу образования в современном государстве. Такое направление развития государства констатируется многими представителями научной среды [2-8]. В этих обстоятельствах информационно-коммуникационные технологии (ИКТ) изменяют систему образования коренным образом, ускоряют возможности формирования больших массивов информации, в частности посредством информационных баз данных, упрощают процессы хранения и поиска, существенно увеличивают возможности ее распространения. Таким образом, ИКТ стали важнейшим источником получения информации, а значит, важнейшим образовательным ресурсом.

В вузах формируется новая информационно-медийная среда, где ИКТ играют роль нового средства создания, хранения, распространения и получения информации. Посредством ИКТ осуществляются различные коммуникации участников образовательного процесса, что повышает в свою очередь и степень коммуникативной свободы участников процесса оценивания знаний и учета текущей успеваемости. Кроме того, среди положительных тенденций внедрения ИКТ в систему учета текущей успеваемости и процедур оценки знаний в вузе можно отнести ее децентрализацию (процесс стирания границ между «центром» и периферией), становление культуры open source (идеи открытого доступа) и др. В связи с чем ИКТ должны быть востребованы и взяты на вооружение участниками процесса управления процедурой оценки знаний и учетом текущей успеваемости, а широкое внедрение и их использование в образовательном процессе должно рассматриваться как немаловажный критерий определения степени успешности деятельности современного вуза.

В настоящее время положение дел в данной сфере в большинстве вузов оставляет желать лучшего. Не сложилось единое киберпространство вуза. Существующие модели учета текущей успеваемости и процедур оценки знаний не взаимосвязаны общей структурой управления в киберпространстве вуза. Формализованные модели процессов учета текущей успеваемости и оценки знаний ввиду их отсутствия не интегрированы в единое информационно-функциональное пространство. Что, в конечном счете, снижает эффективность применения существующих автоматизированных систем управления учебным процессом, не позволяет обеспечить на высоком уровне информационную и интеллектуальную поддержку принятия управленческих решений в системе учета текущей успеваемости и процедур оценки знаний обучаемых. В образовательной среде сложилось противоречие, требующее своего разрешения. С одной стороны, возникла острая необходимость своевременного использования в системе учета текущей успеваемости и процедур оценки

\section{Baikal Research Journal}

электронный научный журнал Байкальского государственного университета 
знаний больших информационных объемов высокого качества и информационных потоков. С другой стороны, констатируется отсутствие возможности оперативно формировать такие объемы и управлять информационными потоками в силу отсутствия информационного и программного обеспечения, а также навыков применения информационных средств и технологий у административного и преподавательского персонала. Да и само массовое и индивидуальное сознание участников образовательной сферы не готово к такой деятельности.

Тем не менее, в условиях достаточно интенсивного развития процесса информатизации в образовательной среде многие цели управления образовательным процессом в вузе на качественно новом уровне становятся вполне достижимыми. Что позволяет решать задачи обеспечения информационной поддержки учебного процесса, а также создавать и применять систему учета текущей успеваемости и процедур оценки знаний на основе сетевых компьютерных технологий, собственно компьютерных сетей и современных инструментальных программных средств.

Поэтому современный этап исследований в данной области связан, прежде всего, с внедрением и практическим использованием ИКТ в деятельности по оцениванию знаний и учету текущей успеваемости обучаемых в вузе. При этом главная задача состоит в том, чтобы лучше понять, каким образом новые информационные технологии могут быть оптимально применены, как для развития системы учета текущей успеваемости и процедур оценки знаний, так и для повышения оптимизации, эффективности и результативности образовательного процесса в целом. В этих целях, прежде всего, необходимо определить пути влияния ИКТ на процесс управления процедурой оценки знаний и учетом текущей успеваемости.

ИКТ влияют на процесс управления процедурой оценки знаний и учетом текущей успеваемости несколькими путями. В первую очередь, ИКТ представляют собой не что иное, как средства производства, инвестиции в которые приведут к повышению производительности труда административного и преподавательского персонала.

Кроме того, ИКТ меняют стратегию персонала вуза по управлению учетом текущей успеваемости и оценки знаний обучаемых путем замены способа функционирования, параллельно влияя на сам процесс производства соответствующего продукта в сфере учета текущей успеваемости и процедур оценки знаний. Более того, они преобразуют сам продукт, т. е. ту совокупность услуг по учету текущей успеваемости и процедур оценки знаний и информации о них, которую персонал предоставляет обучаемым. В результате чего ИКТ позволяет вузу повышать эффективность, а значит, и продуктивность процесса управления процедурой оценки знаний и учетом текущей успеваемости.

В ходе информатизации процесса управления процедурой оценки знаний и учетом текущей успеваемости информационные технологии проникают в каждую точку цепочки взаимодействия сторон коммуникации (администратор - преподаватель - студент), «преобразуя способ выполнения видов деятельности и природу связей между ними» [9]. Посредством ИКТ создается новая киберсреда и новый язык коммуникаций. Ускоряется процесс коммуникации так, что можно с легкостью получать информацию о состоянии процесса оценивания и уровне успеваемости и, соответственно, планировать свою учебную деятельность. ИКТ влияют и на то, каким образом производимый персоналом вуза продукт (результаты текущей успеваемости и процедур оценки знаний) удовлетворяет потребности обучаемых в информации о состоянии оценивания их знаний и успеваемости в целом.

IT-технологии создают особенную форму распределенной коммуникации, благодаря которой включенные в автоматизированные коммуникационные процессы оценивания знаний и учета текущей успеваемости административный и преподава-

\section{Baikal Research Journal}

электронный научный журнал Байкальского государственного университета 
тельский персонал, обслуживающие и использующие эти сети, а также обучаемые, подчиненные заданным технологическим нормам, стали отображать данный вид связи в собственном общении. Их общение в системе учета текущей успеваемости и процедур оценки знаний, «сознательно или бессознательно, оказалось организованным через программу сетевых процессов, заложенную изначально в вычислительную технику. Соответственно, их коммуникация стала формироваться по образу и подобию компьютерных сетей» [10]. Такого рода эффекты вполне объясняют приобретение информационными технологиями стратегической значимости в учебном процессе. Помимо того рост использования ИКТ приводит к усилению «сетевых эффектов» [11], таких как снижение издержек процесса оценивания знаний и учета текущей успеваемости, а также ускорение внедрения инноваций в учебный процесс, что, в свою очередь, повышает общую экономическую эффективность образовательного процесса вуза. В связи с этим Й. Масуда в книге «Информационное общество как постиндустриальное общество» утверждает, что «инновации в информационной технологии - это скрытая сила социальной трансформации, которая выражается в радикальном увеличении количества и качества информации, а также в возрастании объемов обмена информацией» [12].

Специфика образовательного процесса в отличие от любого производственного процесса состоит в объекте, основной деятельности и целях. Бесспорно, что основными видами деятельности вузов является образовательная и научная сферы. Однако в условиях бурной информатизации плодотворность их развития, эффективность и результативность напрямую обусловлены широтой внедрения и профессионализмом применения ИКТ. Широкое использование компьютеров на всех стадиях учебного процесса, включая учет текущей успеваемости и оценку знаний обучаемых, приведет к его повсеместной информатизации. Возможности использования ИКТ довольно широки. Средства информационных технологий улучшают реализацию и расширяют возможности административного и профессорско-преподавательского персонала.

Дальнейшее эффективное развитие системы учета текущей успеваемости и процедур оценки знаний проистекает из представлений математики и логики. Такую систему строят как часть Сети и рассматривают как математический инструмент, предоставляющий «возможность установить количественные соотношения между сетевыми объектами» [13]. Информационные технологии создадут интеллектуальную поддержку принятия управленческих решений в области учета текущей успеваемости и процедур оценки знаний за счет использования алгоритмических, математических и структурных методов. Алгоритмические и математические методы позволят обеспечить формирование управляющих воздействий в системе учета текущей успеваемости и процедур оценки знаний на количественной основе. Структурный подход в свою очередь формализует организацию взаимосвязи процессов управления процедурой оценки знаний и учетом текущей успеваемости за счет интеграции в информационно-функциональную систему и систему автоматизации вуза, способствуя тем самым созданию единого киберпространства. На алгоритмическом уровне информационные технологии отличаются возможностью внедрения элементов обратной связи посредством автоматизированной системы принятия решений, благодаря чему взаимодействие между сторонами коммуникации, представляющее «итерационный процесс формирования управляющих воздействий на основе формализованных экспертных знаний и математических методов» [14], станет более эффективным и результативным.

Внедрение ИКТ позволит поднять на более высокий уровень всю систему управления процедурой оценки знаний и учетом текущей успеваемости в вузе. Начало этому положит разработка и внедрение программного обеспечения процессов управ-

\section{Baikal Research Journal}

электронный научный журнал Байкальского государственного университета 
ления процедурой оценки знаний и учетом текущей успеваемости в виде совокупности программных систем (автоматизированной системы управления текущей успеваемостью и оцениванием знаний обучаемых). Такая система должна отвечать определенным критериям, а именно: локальной автономности; масштабируемости; настраиваемым разграничением полномочий; комплексированием задач в требуемые конфигурации; возможностью распределенной обработки информации; доступом к информации по иерархическому принципу, т. е. в соответствии с иерархической структурой управления полнотой, непротиворечивостью и согласованностью всех данных информационной среды; корректной поддержкой многопользовательской работы; информационной безопасностью [15]. При этом формальное описание элементов базовой модели оценки знаний обучаемых должно включать формализованное описание «пространства свойств» и «пространства баз сравнения»; разработку процедур их отображения в системе критериев оценивания; подготовку процедур структурного обобщения и синтеза оценочной деятельности как сложного, многоуровневого процесса, а также формирование пространства «операторов оценивания» на различных уровнях процесса оценки текущей успеваемости.

Необходимо решать проблему социализации и адаптации административного и преподавательского персонала в киберпространстве системы учета текущей успеваемости и оценки знаний обучаемых. Уверенность в неумении и невозможности создания, получения и использования информации о текущей успеваемости и процессе оценивания знаний посредством ИКТ преодолевается путем формирования особой формы сознания личности - «информатизационного сознания, как специфической формы отражения социальной реальности, направленной на информационные процессы и ИКТ» [16]. В рамках системы учета текущей успеваемости и процесса оценивания знаний модель социализации и адаптации пользователей ИКТ предполагает освоение административным и преподавательским персоналом технологий информационной коммуникации, навигации и правил поведения в компьютерных сетях в ходе текущего оценивания успеваемости, навыков формирования, ориентации и использования базы данных о текущей успеваемости, а также норм и ролевых требований, существующих как в виртуальном сетевом сообществе пользователей баз данных о процессе оценивания знаний и текущей успеваемости обучаемых, так и в киберпространстве вуза в целом. Параллельно освоению норм и ролей в киберпространстве пользователю придется под влиянием информатизации корректировать свое поведение в сообществе пользователей информационной системой оценивания знаний и учета текущей успеваемости, в которой они социализировались. Хотя пользователи такой системы могут столкнуться в ходе информационной коммуникации посредством ИКТ с альтернативными образцами мышления и поведения других участников, тем не менее, это позволит усвоить им конкретные ролевые ориентации и нормативные модели социальных взаимодействий, получить навыки навигации в киберпространстве и взаимодействия с другими пользователями и с контентом, ощутить на себе действие механизмов социального контроля [17].

Одновременно современные информационные технологии, как известно, обладают особой силой наглядности, что влечет усиление эмоционального воздействия и увеличение восприятия обучаемыми соответствующей информации. В свою очередь, данный аспект повышает эффективность влияния на формирование необходимых установок личности обучаемых. Кроме того, большое значение имеет так называемый «эффект сиюминутности присутствия и сопричастности $\kappa$ информации» [18], когда за сравнительно небольшое время обучаемый получает обширную и наглядную информацию, позволяющую сформировать определенные представления о процессе оценивания, состоянии успеваемости и убеждения в необходимости ее корректировки в направлении повышения.

\section{Baikal Research Journal}

электронный научный журнал Байкальского государственного университета 
Следовательно, производство информационного продукта становится на наших глазах движущей силой образования. Формирование киберпространства образовательной среды вуза представляет собой следующий специфический этап развития сферы образования. На данном этапе не только информация, но и информационная коммуникация становятся важной ценностной составляющей и системообразующим фактором, который существенно видоизменяет контуры и структуру системы учета текущей успеваемости и процедур оценки знаний в современном вузе, а также самих участников образовательного процесса. Причем ИКТ видоизменяют не просто качество жизнедеятельности участников информационной коммуникации в системе оценивания знания и учета текущей успеваемости, они трансформируют сам способ их бытия в киберпространстве образовательной среды современного вуза.

\section{Список использованной литературы}

1. Манжуева О. М. Основные направления развития информационных технологий и их влияние на характер современной реальности / О. М. Манжуева // Вестник Бурятского государственного университета. - 2011. - Вып. 14. - С. 90-95.

2. Братищенко В. В. Статистический анализ экзаменационных оценок [Электронный ресурс] / В. В. Братищенко // Известия Иркутской государственной экономической академии (Байкальский государственный университет экономики и права). -2011 . - № 3. - Режим доступа : http://eizvestia.isea.ru/reader/article.aspx?id=8014.htm.

3. Братищенко В. В. Параметрическая модель экзаменационных оценок / В. В. Братищенко // Качество. Инновации. Образование. - 2012. - № 3 (82). - С. 32-35.

4. Кешиков К. А. Влияние информационно-коммуникационных технологий на систему управления учетом текущей успеваемости и процедур оценки знаний в вузе в современном государстве / К. А. Кешиков // Проблемы организации органов государственной власти и местного самоуправления: история, теория, практика и перспективы : сб. науч. тр. / отв. ред. Н. В. Кешикова. - Иркутск : Изд-во БГУЭП, 2015. - С. 225-229.

5 . Кешиков К. А. Трансформация управления процедурой оценки знаний и учетом текущей успеваемости вуза в условиях электронного государства / К. А. Кешиков / Современные проблемы правотворчества и правоприменения : материалы Всерос. студенч. науч.-практ. конф. Иркутск, 11 марта 2016 г. - Иркутск : Иркут. ин-т (фил.) Всерос. гос. ун-т юстиции (Рос. прав. акад. Минюста России), 2016. - С. 56-61.

6. Кешиков К. А. Влияние информационных технологий на систему управления учетом текущей успеваемости и процедур оценки знаний [Электронный ресурс] / К. А. Кешиков // Baikal Research Journal. - 2016. - T. 7, № 1. - DOI : 10.17150/2411-6262.2016.7(1).14.

7. Кешикова Н. В. Философско-методологические основы порядка формирования государственных органов / Н. В. Кешикова. - Иркутск : Изд-во БГУЭП, 2012. - 124 с.

8. Сачков Д. И. Оценка эффективности информационно-телекоммуникационных систем на основе свободного программного обеспечения / Д. И. Сачков, В. В. Братищенко, З. В. Архипова. - Иркутск : Изд-во БГУЭП, 2013. - 156 с.

9. Пресняков Е. В. Влияние информационно-коммуникационных технологий на мировую экономику / Е. В. Пресняков // Известия Санкт-Петербургского университета экономики и финансов. - 2011. - № 1. - С. 132-134.

10. Назарчук А. В. Сетевое общество и его философское осмысление / А. В. Назарчук // Вопросы философии. - 2008. - № 7. - С. 61-75.

11. Плотников В. А. Управление национальной инновационной системой России: кадровый аспект / В. А. Плотников // Известия Санкт-Петербургского университета экономики и финансов. - 2010. - № 3. - С. $42-53$.

12. Вартанова Е. Л. Медиаэкономика зарубежных стран : учеб. пособие / Е. Л. Вартанова. - М. : Аспект Пресс, 2003. - 336 с.

13. Черникова И. В. О влиянии информационных и когнитивных технологий на образовательные стратегии и сознание / И. В. Черникова, Е. В. Середкина // Язык и культура. 2012. - Вып. 4 (20). - С. 128-138.

14. Северцев Н. А. Применение информационной технологии для развития производства / Н. А. Северцев, А. В. Мухин, Ю. Г. Гущин // Труды Международного симпозиума «Надежность и качество». - 2008. - Т. 1. - С. 45-47.

\section{Baikal Research Journal}

электронный научный журнал Байкальского государственного университета 
15. Коджешау М. А. Влияние новых информационных технологий на повышение эффективности управления качеством образования / М. А. Коджешау // Вестник Адыгейского государственного университета. - 2006. - Вып. 1. - С. 245-247.

16. ЖЖилкин В. В. Процесс инфосоциализации в условиях информатизации сознания личности / В. В. Жилкин // Третий Российский культурологический конгресс с международным участием «Креативность в пространстве традиции и инновации» : тез. докл. и сообщений. - СПб. : ЭЙДОС, 2010. - С. 206-217.

17. Бондаренко С. В. Социальная структура виртуальных сетевых сообществ : дис. ... д-ра социол. наук : 22.00.04 / С. В. Бондаренко. - Ростов н/Д, 2004. - 396 с.

18. Ерофеев С. Ю. Криминологический аспект формирования агрессивного поведения несовершеннолетних под воздействием информационных технологий / С. Ю. Ерофеев // Вестник Удмуртского университета. — 2005. — № 6-2. — С. 259-264.

\section{References}

1. Manzhuyeva O. M. The general trends of developing informational technologies and their influence on the character of contemporary reality. Vestnik Buryatskogo gosudarstvennogo universiteta $=$ The Bryansk State University Herald, 2011, iss. 14, pp. 90-95. (In Russian).

2. Bratishenko V. V. Statistic analysis of examination grades. Izvestiya Irkutskoi gosudarst vennoi ekonomicheskoi akademii (Baykalskii gosudarstvennyi universitet ekonomiki $i$ prava) $=$ Bulletin of Irkutsk State Economics Academy (Baikal State University of Economics and Law), 2011, no. 3. Available at: http://eizvestia.isea.ru/reader/article.aspx?id=8014/. (In Russian).

3. Bratishenko V. V. Parametric model of examination grades. Kachestvo. Innovatsii.Obrazovanie = Quality. Innovations. Education, 2012, no. 3, pp. 32-35. (In Russian).

4. Keshikov K. A. Impact information and communication technologies on the system of managing the recording of current academic performance and procedures of knowledge evaluation in the university in the present-day nation state. In Keshikova N. V (ed.). Problemy organizatsii organov gosudarstvennoi vlasti i mestnogo samoupravleniya: istoriya, teoriya, praktika $i$ perspektivy [Problems of organizing bodies of state power and local self-government: history, theory, practice and prospects]. Irkutsk, Baikal State University Economics and Law Publ., 2015, pp. 225-229. (In Russian).

5. Keshikov K. A. Transformation of managing the system of knowledge evaluation and recording of current academic performance of the university in terms of electronic government. Sovremennye problemy pravotvorchestva i pravoprimeneniya. Materialy Vserossiiskoi studencheskoi nauchno-prakticheskoi konferentsii. Irkutsk, 11 marta 2016 g. [Present-day problems of law-making and law enforcement/ Materials of All-Russian Student Science and Practice Conference. Irkutsk, March 11, 2016]. Irkutsk Institute (branch) of All-Russian State University of Justice Publ., 2016, pp. 56-61. (In Russian).

6. Keshikov K. A. Impact of information technology on management system based on the current progress of knowledge and assessment procedures. Baikal Research Journal, 2016, vol. 7, no. 1. DOI: 10.17150/2411-6262.2016.7(1).14. (In Russian).

7. Keshikova N. V. Filosofsko-metodologicheskie osnovy poryadka formirovaniya gosudarstvennykh organov [Philosophic and methodological foundations of the procedure of public authorities' formation]. Irkutsk, Baikal State University Economics and Law Publ., 2012. 124 p.

8. Sachkov D. I., Bratishchenko V. V., Arkhipova Z. V. Otsenka effektivnosti informatsionno-telekommunikatsionnykh sistem na osnove svobodnogo programmnogo obespecheniya [Efficiency estimation for information and telecommunication systems on the basis of free software]. Irkutsk, Baikal State University of Economics and Law Publ., 2013. 156 p.

9. Presnyakov E. V. Impact of information and communication technologies on the world economy. Izvestiya Sankt-Peterburgskogo universiteta ekonomiki $i$ finansov $=$ Bulletin of Saint-Petersburg University of Economics and Finance, 2011, no. 1, pp. 132-134. (In Russian).

10. Nazarchuk A. V. Network society and its philosophical judgment. Voprosy filosofii $=I s$ sues of Philosophy, 2008, no. 7, pp. 61-75. (In Russian).

11. Plotnikov V. A. Management of Russia's national innovative system: a personnel aspect. Izvestiya Sankt-Peterburgskogo universiteta ekonomiki $i$ finansov = Bulletin of Saint-Petersburg University of Economics and Finance, 2010, no. 3, pp. 42-53. (In Russian).

12. Vartanova E. L. Mediaekonomika zarubezhnykh stran [Media-economy of foreign countries]. Moscow, Aspekt Press, 2003. 336 p.

\section{Baikal Research Journal}

электронный научный журнал Байкальского государственного университета 
13. Chernikova I. V., Seredkina E. V. On the influence of information and cognitive technologies on education strategies and conscience. Yazyk $i$ kul'tura $=$ Language and Culture, 2012, iss. 4 (20), pp. 128-138. (In Russian).

14. Severtsev N. A., Mukhin A. V., Gushchin Yu. G. Use of information technologies for industrial development. Trudy Mezhdunarodnogo simpoziuma "Nadezhnost' $i$ kachestvo" = Procedings of International Symposium «Security and Quality», 2008, vol. 1, pp. 45-47. (In Russian).

15. Kodzheshau M. A. Influence of new information technologies on increasing efficiency of managing the quality of education. Vestnik Adygeiskogo gosudarstvennogo universiteta = Bulletin of Adyghe State University, 2006, iss. 1, pp. 245-247. (In Russian).

16. Zhilkin V. V. Process of infosocialization in terms of informatization of personal consciousness. Tretii Rossiiskii kul'turologicheskii kongress s mezhdunarodnym uchastiem "Kreativ nost' $v$ prostranstve traditsii i innovatsii» [Third Russian culturological congress Saint Petersburg, EIDOS Publ., 2010, pp. 206-217. (In Russian).

17. Bondarenko S. V. Sotsial'naya struktura virtual'nykh setevykh soobshchestv. Dokt. Diss. [Social structure of virtual network communities. Doct. Diss.]. Rostov-on-Don, 2004. 396 p.

18. Erofeyev S. Yu. Criminological aspect of developing aggressive behavior of the non-adult affected by information technologies Vestnik Udmurtskogo universiteta = Bulletin of Udmurt University, 2005, no. 6-2, pp. 259-264. (In Russian).

\section{Информация об авторе}

Кешиков Константин Андреевич - аспирант, кафедра информатики и кибернетики, Байкальский государственный университет, 664003, г. Иркутск, ул. Ленина, 11, e-mail: const2k@mail.ru.

\section{Author}

Konstantin A. Keshikov - PhD Student, Chair of Computer Science and Cybernetics, Baikal State University, 11 Lenin St., 664003, Irkutsk, Russian Federation, e-mail: const2k@mail.ru.

\section{Библиографическое описание статьи}

Кешиков К. А. Пути влияния информационно-коммуникационных технологий на систему управления процедурой оценки знаний и учет текущей успеваемости в современном вузе / К. А. Кешиков / / Baikal Research Journal. — 2016. — T. 7, № 4. — DOI : 10.17150/24116262.2016.7(4).24.

\section{Reference to article}

Keshikov K. A. Ways of influence of information and communication technologies on system of managing the procedure of knowledge evaluation and recording of current academic performance in present-day universities. Baikal Research Journal, 2016, vol. 7, no. 4. DOI : 10.17150/2411-6262.2016.7(4).24. (In Russian).

\section{Baikal Research Journal}

